\title{
ВMJ Global Health Breast feeding initiation rate across Western countries: does religion matter? An ecological study
}

\author{
Jonathan Y Bernard, ${ }^{1,2,3}$ Emmanuel Cohen, ${ }^{4,5}$ Michael S Kramer ${ }^{6,7,8}$
}

To cite: Bernard JY, Cohen E, Kramer MS. Breast feeding initiation rate across Western countries: does religion matter? An ecological study. BMJ Global Health 2016;1: e000151. doi:10.1136/ bmjgh-2016-000151

Received 8 August 2016 Revised 26 September 2016 Accepted 27 September 2016

CrossMark

For numbered affiliations see end of article.

\section{Correspondence to} Dr Jonathan Y Bernard; jonathan.bernard@inserm.fr

\section{ABSTRACT}

Background: Breast feeding initiation rates remain below $80 \%$ in some Western countries. Many individual-level determinants are known; however, less is known regarding cultural and societal determinants, such as religion, that could explain population-level variations. We examined the correlations of the proportions of Catholics and Protestants with the breast feeding initiation rates across and within Western countries.

Methods: Using publicly available data, we carried out an ecological study comparing the proportions of Catholics and Protestants with the rates of breast feeding initiation. We correlated data at the country level, and additionally explored within-country data in five Western countries: France (Departments), Ireland (counties), the UK (countries), Canada (provinces) and the USA (states). Our analyses accounted for human development index, gross domestic product and population density.

Results: We observed a negative correlation $(r=-0.30)$ between the proportion of Catholics and the rate of breast feeding initiation in Western countries. This correlation was consistent when using within-country data in France $(r=-0.27)$, Ireland $(r=-0.23)$, the UK $(r=-0.79)$ and Canada $(r=-0.62)$. In the USA, the positive correlation ( $r=0.26)$ between a state's proportion of Catholics and its breast feeding initiation rate was confounded by race, education and socioeconomic status (SES). After controlling for education and SES, the state proportion of nonHispanic white Catholics was negatively correlated $(r=-0.29)$ with the rate of breast feeding initiation. Conclusions: In this ecological study, we found consistent negative correlations between Catholicism and breast feeding initiation rates. Qualitative and quantitative studies at the individual level are needed to confirm and explain our findings. Our results suggest that women living in a country or region where Catholicism has historically dominated are less likely to initiate breast feeding, and that breast feeding promotion policies should be adapted to better fit populations' cultural and religious norms.

\section{INTRODUCTION}

The presence of mammary glands and the female's ability to lactate/breastfeed are key
Key questions

What is already known about this topic?

- Despite the WHO's recommendations promoting breast feeding, wide variations in breast feeding initiation rates are observed among Western countries, with some reaching $>95 \%$, while others remain $<80 \%$.

- Many individual-level determinants of breast feeding are known, such as maternal age, education and previous breast feeding experience.

- Less is known regarding cultural and societal determinants, such as religion, which could explain population-level differences between and within countries.

\section{What are the new findings?}

- In Western countries, the proportion of Catholics is negatively correlated with the rate of breast feeding initiation.

- This negative correlation is also observed within countries in France, Ireland, the UK and Canada, and among non-Hispanic whites in the USA.

- Western countries with a higher proportion of Protestants are closer to meeting the WHO's recommendations.

\section{Recommendations for policy}

- Our study suggests religion as a population-level determinant of breast feeding initiation in Western countries; this knowledge could help refine breast feeding promotion policies in countries and areas with larger Catholic populations.

- More research is needed to understand potential underlying mechanisms relating breast feeding practice to religious and cultural values and customs.

features of all mammals, including humans. ${ }^{1} 2$ Yet breast feeding among modern humans is strongly influenced by cultural values, beliefs and customs, leading to variations in breast feeding practices. ${ }^{3}$

Many studies reported benefits of breast feeding (vs formula feeding) for the shortterm and long-term health of the offspring and the mother. ${ }^{4}$ The WHO now recommends exclusive breast feeding for 6 months 
and continued partial breast feeding to 2 years. ${ }^{6}$ In most countries, whether high income or low income, rates of breast feeding initiation exceed 90\%, although its recommended exclusivity and duration are rarely attained. In Western countries, where initiation rates reached a low in the mid-20th century, considerable public health efforts have been made to promote and support breast feeding. Countries from Northern Europe have since increased initiation rates to as high as $95 \% .^{7}$ However, rates remain below $80 \%$ in several European countries, especially in Southern Europe (76\%, 65\% and 62\%, respectively, in Spain, France and Malta). ${ }^{7}$ This apparent north-south gradient in breast feeding initiation rates has a few notable counterexamples, including Ireland (46\%), Northern Ireland (64\%) and Poland $(71 \%) .{ }^{7}$ In Canada and in the USA, breast feeding initiation rates were $87 \%$ and $75 \%$, respectively, in 2010. ${ }^{9}$ Canada has a strong west-east gradient, with Quebec and the Atlantic provinces reporting the lowest rates. The USA has a prominent northwest-southeast gradient, with some south-eastern states reporting breast feeding initiation rates below 30\%; this state variation remains even after accounting for key determinants such as ethnicity and socioeconomic status (SES). ${ }^{10}$

A number of determinants of breast feeding practices have been identified and categorised into five groups: ${ }^{11}$ (1) demographic (age, ethnicity, education, SES, employment), (2) psychosocial (maternal confidence, health belief, relative support), (3) healthcare factors and biomedical constraints (promotion, training, individual health), (4) community attributes (social networks and norms/standards, peer support groups) and (5) public policy (eg, laws on maternity benefits). When asked, mothers who choose not to breastfeed mention individual-level determinants (lack of confidence, pain and difficulties, lack of milk, return to work, embarrassment to publicly breastfeed). ${ }^{12-15}$ This makes it difficult to identify underlying determinants at the population level that are likely to explain between-country variations. Yet, as outlined by Bourdieu, ${ }^{16}$ individual norms and habits may be driven by sociocultural norms-'the habitus' - which can underlie individual choices.

From a socioanthropological standpoint, individuallevel and population-level determinants share systems of customs, beliefs and values, including religious culture. Religious culture may influence individual health practices, as highlighted by Durkheim and Weber in their seminal work on suicide rates and self-esteem in Catholics and Protestants. ${ }^{17} 18$ Based on their theoretical framework, more recent studies have identified associations between sociocultural traits and individual health perceptions and practices. ${ }^{19-21}$ Women's choice to breastfeed (or not) are therefore likely to be influenced by religious culture or adherence to traditional or modern values. We hypothesised that Catholicism and Protestantism may influence breast feeding practice across and within countries, particularly in Western countries where these two religious cultures are historically grounded.
By collating publicly available online data, we carried out an ecological study to assess the association between the proportions of Catholics and Protestants and rates of breast feeding initiation. Since such an approach requires sufficient statistical variability for both the independent and dependent variables, we focused on Western countries. We also studied within-country regional variations in five Western countries for which we found data: France, Ireland, the UK, Canada and the USA.

\section{METHODS}

\section{Country data}

Country-level proportions of Roman Catholics and Protestants were gathered from the Pew Research Centre database $^{22}$ and, when missing there, from the Central Intelligence Agency's World Factbook 2013-2014. ${ }^{23}$ Breast feeding initiation rates were obtained from the online databases of the $\mathrm{WHO}^{24}$ and, for its members, from the Organisation for Economic Co-operation and Development. ${ }^{25}$ The gross domestic product (GDP) per capita was obtained from the Central Intelligence Agency's World Factbook 2013-2014, ${ }^{23}$ and the 2014 Human Development Index (HDI) from the 2015 Human Development Report of the United Nations Development Programme. ${ }^{26}$

\section{French department data}

The proportions of Roman Catholics, Protestants and 'no religion' in French Departments were obtained from data collected between 2003 and 2006 by the polling company 'Institut français d'opinion publique' (Ifop, French Institute of Public Opinion). ${ }^{27}$ This survey was based on a cumulative, representative sample of 91559 interviews; data were available for 94 of the 101 French administrative Departments. Breast feeding initiation rates by Department were obtained from the 'Child Health Certificate on the 8th Day', a national survey whose data are available on the website of the 'Direction de la recherche, des études, de l'évaluation et des statistiques' (Dress, French Direction of Research, Studies, Evaluation and Statistics). ${ }^{28}$ Yearly data over the period 2006-2013 were collated and averaged to smooth variations and overcome sporadic missing data for a few Departments. GDP (in 2005) and population density (in 2006) by Department were obtained from the 'Institut national de la statistique et des études économiques' (Insee, National Institute of Statistics and Economic Studies).

\section{Irish county data}

Religion proportions (Roman Catholics, Anglicans (Church of Ireland) and 'no religion'), population density and GDP in Irish counties were collated from the Irish Census 2011 available on the Central Statistics Office website. ${ }^{29}$ Breast feeding initiation rates were from the Perinatal Statistics Report 2011. ${ }^{30}$ 


\section{UK country data}

Religion proportions (Roman Catholics, Anglicans and 'no religion') in England, Wales, Scotland and Northern Ireland were obtained from their respective 2001 censuses. ${ }^{31-33}$ Data on breast feeding were obtained from the United Nations Children's Emergency Fund UK website. $^{34}$ Regional gross value added in 2014 was obtained from data published by the Office for National Statistics and population density was derived from the 2011 Census.

\section{Canadian province data}

Religion proportions (Roman Catholics, Protestants and 'no religion') and breast feeding data were collated on the Statistics Canada website, from the 2011 National Household Survey (religion) and the 2009-2010 Canadian Community Health Survey (breast feeding). ${ }^{13} 35$ GDP per capita in 2014 and population density in 2011 were also obtained from the Statistics Canada website.

\section{US state data}

Proportions of Roman Catholics, Evangelical Protestants, Mainline Protestants and 'no religion' in US states were obtained from the 2014 survey of the 'Public Religion Research Institute', available on the 'American Values Atlas project' website. ${ }^{36}$ That survey also includes ethnicspecific religion data (ie, white Evangelical Protestants, black Protestants, non-Hispanic white Catholics). State-level data on ethnicity proportion (state percentage of non-Hispanic whites, Hispanic whites and Blacks), educational attainment (\% of population with a high school degree or less) and household income (\% of population with $<\$ 30000 /$ year) were also gathered on this website. State-level data on breast feeding were from the '2010 National Immunization Survey' conducted by the Centers for Disease and Control and Prevention. ${ }^{9}$ Ethnic-specific breast feeding initiation rates by state were also available for non-Hispanic whites $(n=50$ states), Hispanic whites $(\mathrm{n}=44)$ and blacks $(\mathrm{n}=26)$.

\section{Statistical analyses}

Frequency distributions for religion and breast feeding initiation were visually inspected. Spearman's unadjusted and partial correlations were used to assess the relationship between country-level proportions of Catholics and Protestants and of breast feeding initiation. This analysis was stratified by world subregion and adjusted for GDP per capita and for HDI (separately, since GDP per capita is accounted for in the HDI). The Western subregion was defined as European countries plus Cyprus, Canada, the USA, Australia and New Zealand.

Spearman (rank) correlation coefficients were used to compare religion proportions with breast feeding initiation rates using within-country data, namely French Departments, Irish counties, UK countries, Canadian provinces and US states. For UK data, we used the more statistically powerful Pearson correlation coefficient because of the small number of countries. Correlations were adjusted for GDP per capita (to account for withincountry economic wealth differences) and population density (to account for urbanisation, since populations living in rural areas are usually older, less educated and more traditional in religious practice). We also plotted the proportion of Catholics (x-axis) against breast feeding initiation rates (y-axis). For US states, the analysis was performed both overall and by ethnicity and adjusted for state-level rates of low education and low SES (both factors being strongly related to both religion and breast feeding initiation).

Analyses were performed using SAS V.9.4 (SAS Institute, Cary, North Carolina, USA).

\section{RESULTS}

The average proportions of Catholics and Protestants in Western ( $\mathrm{n}=37)$, Sub-Saharan African $(\mathrm{n}=37)$ and Central and Southern American $(n=18)$ countries varied between $19 \%$ and $68 \%$ (table 1). Although the Central and South American subregion had the highest Catholic proportion $(68 \pm 14 \%)$, and the Sub-Saharan African subregion the highest Protestant proportion $(32 \pm 26 \%)$, the Western subregion had the widest variability for both Christian religions. The Western subregion also had the lowest breast feeding initiation rate and the largest variability $(87 \pm 12 \%)$; rates in the other subregions were around $95 \%$.

In Western countries, the breast feeding initiation rate was negatively correlated with the proportion of Catholics $(\mathrm{r}=-0.30)$ and positively correlated with the proportion of Protestants ( $\mathrm{r}=0.31$ ) (table 2). These correlations were unchanged $(\mathrm{r}=-0.30)$ or enhanced $(\mathrm{r}=-0.40)$ after controlling for GDP per capita and for HDI, respectively.

The scatter plot of the negative relationship between Catholic proportion and breast feeding initiation rate in Western countries is shown in figure 1. This correlation was not observed in non-Western countries; however, the

Table 1 Country proportions of Catholics and Protestants and breast feeding initiation rates by subregion

\begin{tabular}{|c|c|c|c|c|}
\hline $\begin{array}{l}\text { World } \\
\text { subregion }\end{array}$ & $\mathbf{n}$ & $\begin{array}{l}\text { Catholic } \\
\text { proportion } \\
(\%)\end{array}$ & $\begin{array}{l}\text { Protestant } \\
\text { proportion } \\
(\%)\end{array}$ & $\begin{array}{l}\text { Breast } \\
\text { feeding } \\
\text { initiation } \\
\text { rate (\%) }\end{array}$ \\
\hline Western & 37 & $40.2 \pm 34.6$ & $22.1 \pm 28.2$ & $87.2 \pm 12.2$ \\
\hline $\begin{array}{l}\text { Sub-Saharan } \\
\text { African }\end{array}$ & 37 & $23.2 \pm 18.8$ & $32.5 \pm 25.8$ & $95.6 \pm 3.7$ \\
\hline $\begin{array}{l}\text { Central and } \\
\text { South } \\
\text { American }\end{array}$ & 18 & $68.3 \pm 14.0$ & $19.3 \pm 11.4$ & $95.2 \pm 2.2$ \\
\hline Asian & 25 & $8.3 \pm 24.6$ & $2.4 \pm 3.1$ & $95.1 \pm 3.7$ \\
\hline $\begin{array}{l}\text { North African } \\
\text { and Middle } \\
\text { Eastern }\end{array}$ & 18 & $4.2 \pm 7.2$ & $0.7 \pm 1.1$ & $93.8 \pm 3.6$ \\
\hline
\end{tabular}

Values are Mean \pm SD. 
Table 2 Correlations between Catholic and Protestant proportions and breast feeding initiation rates, by subregion

\begin{tabular}{|c|c|c|}
\hline World subregion & $\begin{array}{l}\text { Catholic } \\
\text { proportion }\end{array}$ & $\begin{array}{l}\text { Protestant } \\
\text { proportion }\end{array}$ \\
\hline Western & $\mathrm{n}=37$ & \\
\hline Unadjusted & -0.30 & 0.31 \\
\hline Adjusted for GDP per capita & -0.30 & $0.42^{*}$ \\
\hline Adjusted for HDI & -0.30 & $0.40^{*}$ \\
\hline Sub-Saharan African & $\mathrm{n}=37$ & \\
\hline Unadjusted & 0.03 & -0.16 \\
\hline Adjusted for GDP per capita & 0.17 & -0.04 \\
\hline Adjusted for HDI & 0.30 & 0.09 \\
\hline Central and South American & $\mathrm{n}=18$ & \\
\hline Unadjusted & 0.02 & -0.16 \\
\hline Adjusted for GDP per capita & 0.05 & -0.32 \\
\hline Adjusted for HDI & 0.02 & -0.22 \\
\hline Asian & $n=24$ & \\
\hline Unadjusted & -0.38 & -0.56 \\
\hline Adjusted for GDP per capita & -0.26 & $-0.49^{*}$ \\
\hline Adjusted for HDI & -0.34 & $-0.53^{\star *}$ \\
\hline North African and Middle Eastern & $\mathrm{n}=18$ & \\
\hline Unadjusted & -0.24 & -0.11 \\
\hline Adjusted for GDP per capita & -0.13 & 0.03 \\
\hline Adjusted for HDI & -0.15 & 0.01 \\
\hline
\end{tabular}

Values are coefficient of Spearman's correlation.

p Values: ${ }^{*}<0.05,{ }^{* *}<0.01$.

GDP, gross domestic product; HDI, human development index.

breast feeding initiation rate in the most Christian country in Asia, the Philippines (81\% Catholic), was lower than in the other Asian countries $(87.7 \%$ vs $95.4 \%$ on average). To a lesser extent, this was also observed for Lebanon versus other North African and Middle Eastern countries (29\% vs 3\% Catholics, on average): $89 \%$ versus $94 \%$ breast feeding initiation.

Based on within-country data, negative correlations were observed between the proportion of Catholics and the breast feeding initiation rate in French Departments $(\mathrm{n}=94 ; \mathrm{r}=-0.31)$, Irish counties $(\mathrm{n}=26 ; \mathrm{r}=-0.41)$, Canadian provinces $(\mathrm{n}=13 ; \mathrm{r}=-0.75)$ and UK countries $(\mathrm{n}=4 ; \mathrm{r}=-0.78)$ (figure 2$)$. These correlations remained strongly negative after controlling for GDP per capita and population density (table 3 ). The direction and the strength of the (adjusted) correlations between breast feeding initiation rates and proportions of Protestants were not consistent across the four countries. The proportions of 'no religion' were positively correlated with breast feeding initiation rates in Ireland $(r=0.38)$, the UK ( $\mathrm{r}=0.93)$ and Canada ( $\mathrm{r}=0.74)$, but weak and negative in France $(\mathrm{r}=-0.07)$.

In the US, state-level rates of breast feeding initiation were positively correlated $(\mathrm{r}=0.26)$ with state-level proportions of Catholics and negatively correlated $(\mathrm{r}=-0.65)$ with state-level proportions of Protestants (table 4). After accounting for state-level rates of low education and low SES, the correlation with the proportion of Catholics was highly attenuated $(\mathrm{r}=0.06)$, while the correlation with the proportion of Protestants almost halved $(\mathrm{r}=-0.37)$. The breast feeding initiation rate among non-Hispanic white Americans was negatively correlated with the proportion of white Catholics ( $r=$ -0.29 ), while only weak correlations were observed with the proportions of white Evangelical $(\mathrm{r}=-0.13)$ and white Mainline $(\mathrm{r}=-0.07)$ Protestants. The negative correlation between the proportion of Protestants and breast feeding initiation rate among all ethnicities was driven by the relationship between the state-level proportion of black Protestants and state-level rates of breast feeding initiation among blacks $(\mathrm{r}=-0.47)$. This correlation was attenuated, however, after controlling for low education and SES $(r=-0.23)$. Finally, the state-level proportion of 'no religion' was positively related to its breast feeding initiation rate, even after controlling for low education and SES ( $\mathrm{r}=0.43)$.

\section{DISCUSSION}

Using an ecological study design, we observed a strong negative correlation between the proportion of Catholics and the rate of breast feeding initiation in Western countries. Countries in which the breast feeding initiation rate was below $80 \%$ are historically Catholic (eg, France, Poland and Ireland). This negative correlation was consistent when using within-country data in France, Ireland, the UK and Canada. In the USA, the positive correlation between a state's proportion of Catholics and its breast feeding initiation rate was confounded by ethnicity, low education and low SES: after controlling, the state proportion of non-Hispanic white Catholics was negatively correlated with its rate of breast feeding initiation.

To the best of our knowledge, ours is the first ecological study to assess the association between the proportions of Catholics and Protestants and breast feeding initiation rates. Previously, one American multicentre study of 4166 families living in urban areas found that Conservative Protestants were more likely to breastfeed $(\mathrm{OR}=1.60,95 \%$ CI not given) than participants who declared no religious affiliation, after controlling for sociodemographic variables, including ethnicity and education. ${ }^{37}$ Catholics were non-significantly less likely to breastfeed compared to participants without religion ( $\mathrm{OR}=0.80,95 \%$ CI not given). Our ecological design has several strengths, including cost and convenience of using publicly accessible secondary data covering 135 countries in five world subregions, which would be infeasible using individual-level data. Moreover, in some countries, individual data on religion, when available, are highly sensitive and their collection is often forbidden by authorities. Finally, the ecological design is appropriate for inferring relationships at the population 


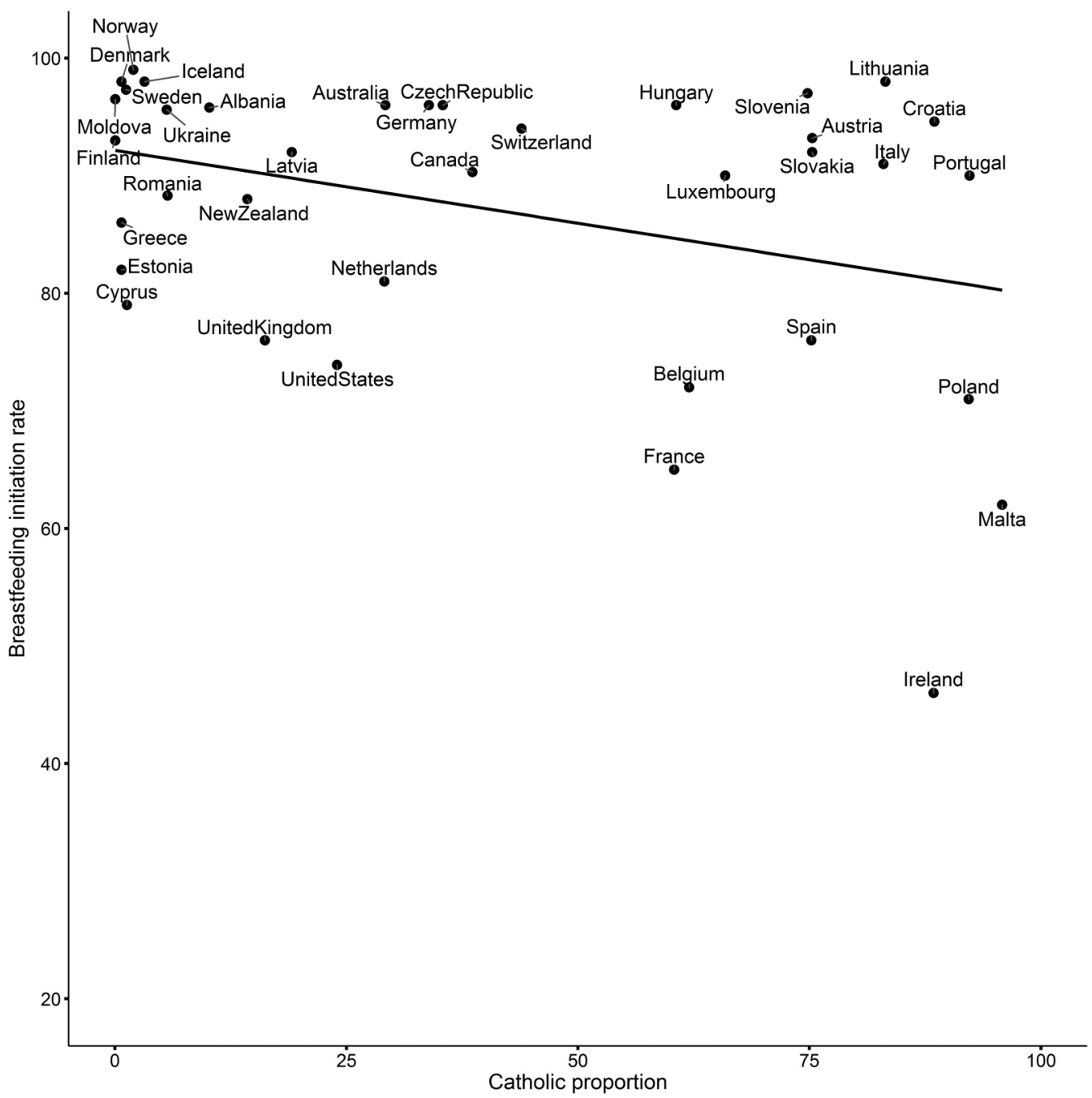

Figure 1 Relationship between Catholic proportion ( $x$-axis) and breast feeding initiation rate (y-axis) in Western countries.

level, such as the potential roles of national/regional policies and sociocultural differences.

The parallel limitation of our study is the so-called ecological fallacy, whereby associations observed at the population level may not reflect relationships at the individual level. To at least partly overcome this limitation, we explored the association using within-country data in France, Ireland, the UK, Canada and the USA; the results of those analyses confirmed our findings. Our analysis for the USA would have been even more informative if breast feeding data had been aggregated at the county level, as we were able to find for religion data. Finally, testing our hypothesis in Germany with Länder-level data would have been an additional asset to our study. Indeed, the Protestant religion originated in Saxony in the 16th century, before spreading to neighbouring areas with a previous Catholic tradition. Unfortunately, we were unable to find data on religion and breast feeding at the Länder level.

Another study limitation is the lack of time-series data. Indeed, our data were cross-sectional snapshots taken in a recent period, while breast feeding initiation rates in
Western countries have been increasing for several decades. Correlating longitudinal data would have strengthened our ability to infer causality for the associations we observed. Nonetheless, we argue that religion proportions and religious culture change too slowly to have significant short-term consequences on breast feeding practice. In fact, adherence or practice of religion, as declared by individuals, are proxies for values and beliefs reflected by religion. Individuals who declare not adhering to any religion, or adhering to one religion without practising it, tend to maintain (perhaps unconsciously) the beliefs and values embedded through generations by their familial and national religious culture. ${ }^{38}$ Hence, it is unlikely that using religion data from the mid-20th century would have changed our results. On the other hand, using breast feeding data from the 1970s or 1980s could have impacted our results; we found no detailed data to compare that temporal change between or within countries. A final limitation of our study is our inability to account for small religious minorities and for potential individual-level confounders such as maternal age, marital status and employment. 


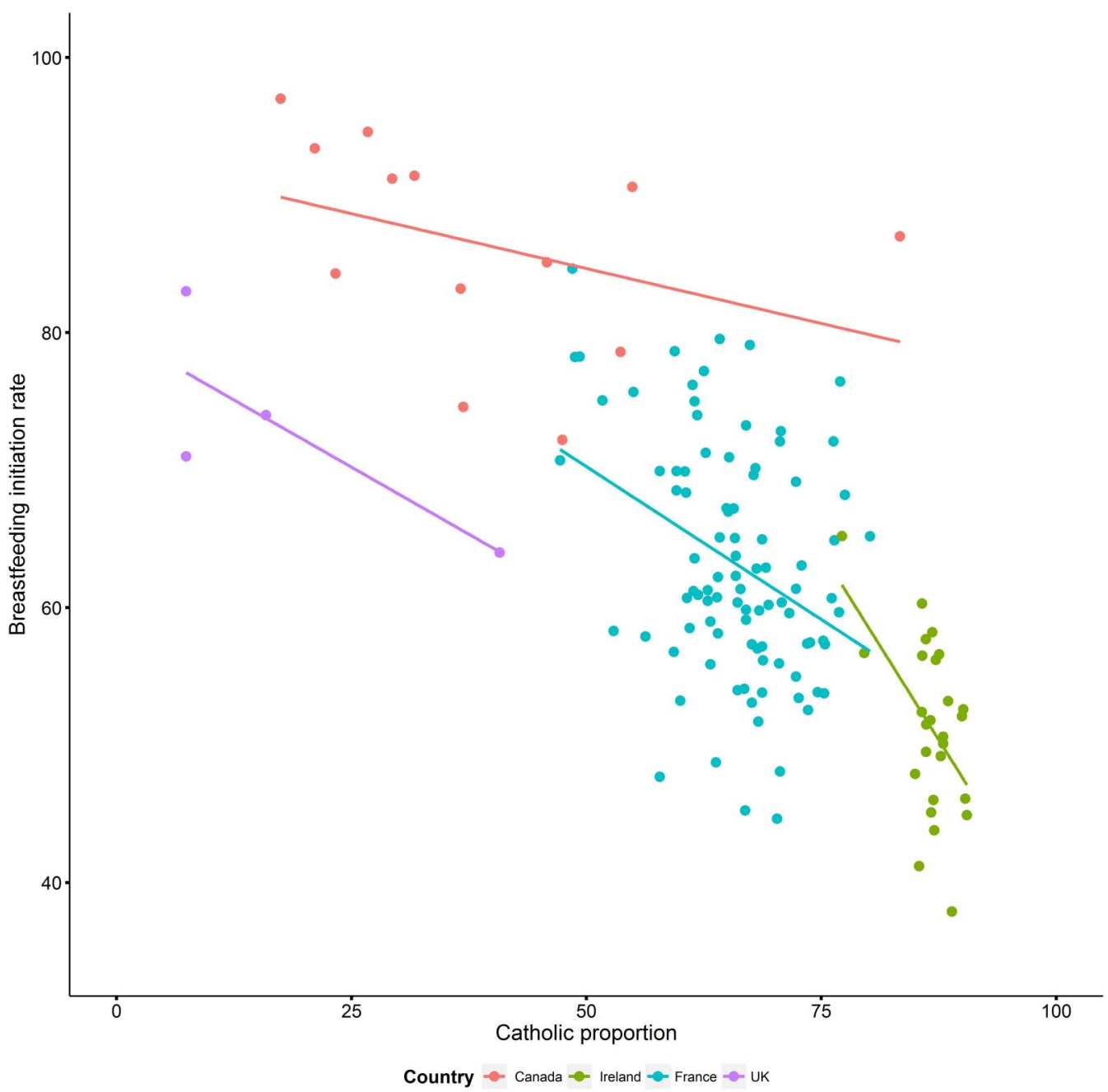

Figure 2 Relationship between Catholic proportions (x-axis) and breast feeding initiation rates (y-axis) in French Departments (cyan), Irish counties (green), UK countries (purple) and Canadian provinces (red).

Our main finding is the negative correlation between the proportion of Catholics and the breast feeding initiation rate among and within Western countries. Conversely, Protestantism was positively correlated with breast feeding initiation rates in country-level analysis, although that correlation was less consistent using within-country data. It is unclear whether these opposite relationships are the consequence of 'communicating vessels' or whether each of these two religious affiliations has an independent effect. Christian countries with higher proportions of Catholics tend to have lower breast feeding initiation rates, whereas rates in predominantly Protestant and non-Christian countries are closer to one another. However, results in African and Central and Southern American countries, although mostly Christian, were not in line with those from Western countries.

Our explanation for these findings draws on both history and theology. First, populations in low-income countries never experienced a widespread shift from breast feeding to formula feeding, in contrast to Western populations at the end of the 19th century. ${ }^{3} 39$ Hence, breast feeding remained the norm in low-income countries, because no affordable alternatives were available for most of the population, even in areas under Western colonial influence. Despite the colonial Christian influence, native populations also probably remained under the broad influence of their traditional beliefs and customs, especially animistic conceptions of the body that value the fertility and the nurturing status of women as symbols of strength, vitality and prosperity. ${ }^{40}$

In Europe, it has been reported that Catholic mothers were less likely to breastfeed than Protestant mothers during the 16th and 17th centuries. ${ }^{3}$ In France, wet nurses were commonly hired to feed infants, especially in Catholic families from the middle and upper classes. ${ }^{41}$ Non-breastfeeding mothers reported concerns about health, pain and body self-image to explain their choice, while sex and lactation were judged incompatible by the Catholic Church, with predictable consequences on breast feeding practice in Catholic households. ${ }^{42}$

From the 19th century, the technological and industrial revolution provided new infant feeding alternatives, 
Table 3 Correlations between Catholic and Protestant proportions and breast feeding initiation rates in French Departments, Irish counties and Canadian provinces

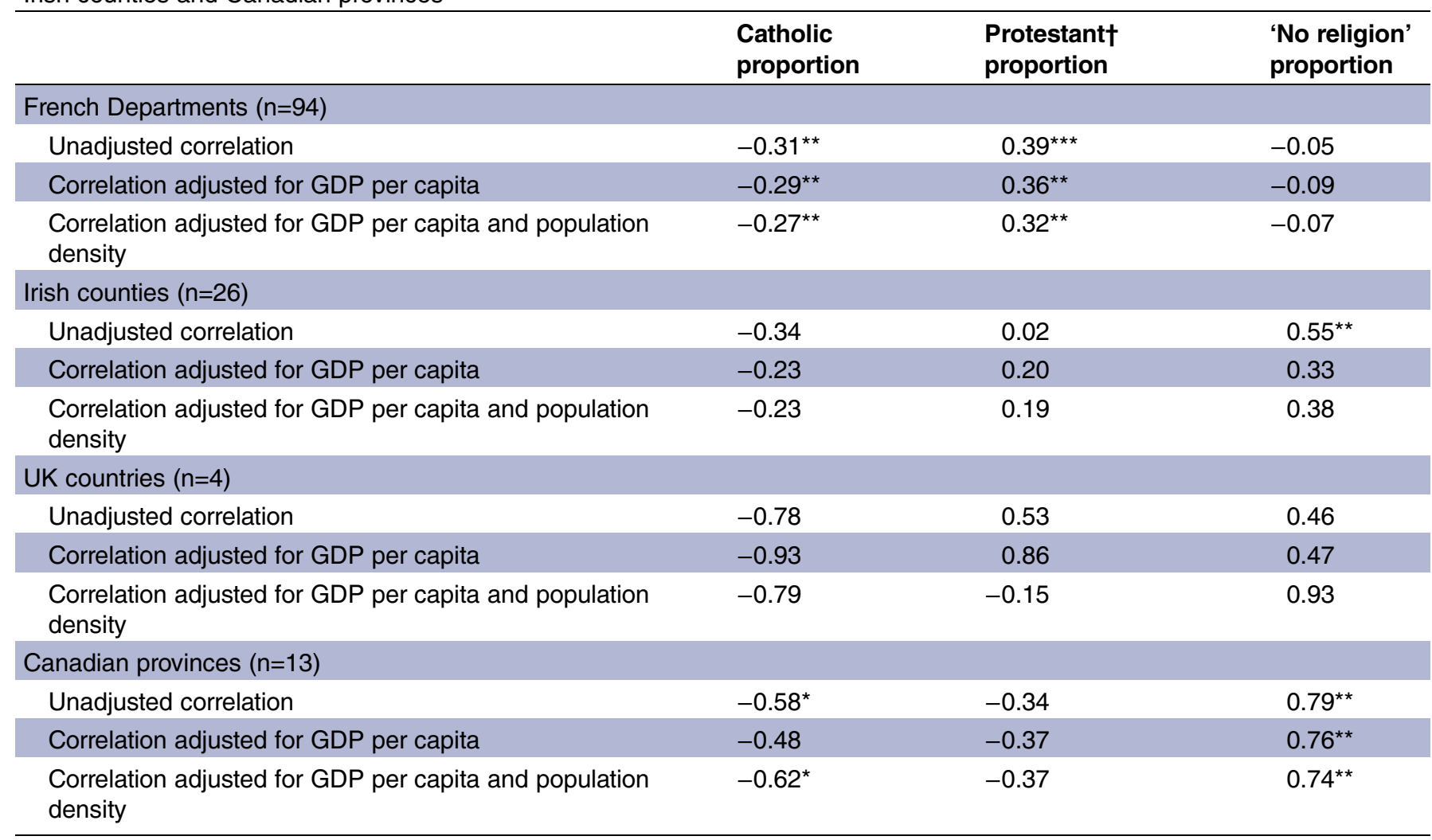

Values are coefficient of Spearman's correlation, except for UK countries (Pearson's correlation).

p Values: ${ }^{*}<0.05,{ }^{* *}<0.01,{ }^{* * *}<0.001$.

GDP, gross domestic product.

†Refers to all Protestant churches for France and Canada, to the Anglican Church of Ireland, and to all Anglican and Protestant churches for the UK.

although they first led to high mortality rates due to poor hygienic conditions. At the end of the 19th century, sterile infant formula and running water became increasingly available and affordable for rural and lower-class urban populations. ${ }^{3}$ Until the 1960s, infant formula was considered as safe as breast milk and a symbol of progress, improving women's conditions and, as a consequence, reducing breast feeding rates to their lowest level in human history. Despite improvements in the nutritional composition of infant formulas, scientific studies began to report health benefits of breast feeding ${ }^{43}$ and breast feeding support movements emerged in the 1970s. ${ }^{3}$ Prior to this recent promotion phase, it remains unclear whether Catholics and Protestants started from the same low baseline. In the 1970 s, breast feeding initiation rates were $36 \%$ in France, $11-24 \%$ in Ireland, 26\% in Canada, $24 \%$ in the USA and around $35 \%$ in Sweden. ${ }^{12}{ }^{44-47}$ Protestant countries then experienced a faster increase, as illustrated by the current statistics. ${ }^{7}$ One plausible interpretation is that Protestants, through individual behaviours or public policies, may be more inclined to adopt scientific recommendations and quicker to implement new health promotion policies. As explained by Weber, ${ }^{17}$ the Protestant ethic promotes pragmatism and utilitarianism as ways to achieve modern progress and salvation. In contrast, the Catholic ethic tends to be more sceptical towards novelty and therefore may be less adaptable and dynamic when faced with new scientific recommendations. ${ }^{40}$ These two distinct conceptions of modern progress could influence modern society by promoting different values, which are then translated into different lifestyles and behaviours. ${ }^{48}$ This could be mediated, among others factors, by the societal acceptance of breast feeding in public, which has been shown to be associated with breast feeding practice in four European countries. ${ }^{49}$

\section{CONCLUSION}

In conclusion, our ecological analysis suggests a new population-level factor influencing breast feeding initiation across and within Western countries: the proportion of Catholics. This observation may help policymakers and healthcare professionals target at-risk populations and reinforce or adapt their breast feeding promotional efforts according to sociocultural background. Individual-level studies are needed to confirm or refute our findings. Qualitative studies are also necessary to identify the sociocultural values and beliefs that mediate the relationships between a historically Catholic family or societal background and breast feeding 
Table 4 Correlations between proportions of Catholic, Protestant and no declared religion and breast feeding initiation rates in the American states

\begin{tabular}{ll} 
Breast feeding initiation rate among \\
\hline $\begin{array}{ll}\text { All ethnicities } & \text { Non-Hispanic white } \\
(n=50) & (n=50)\end{array}$
\end{tabular}

Hispanic white
$(\mathrm{n}=44)$

Blacks

$(\mathrm{n}=26)$

\section{Catholics}

Total Catholics

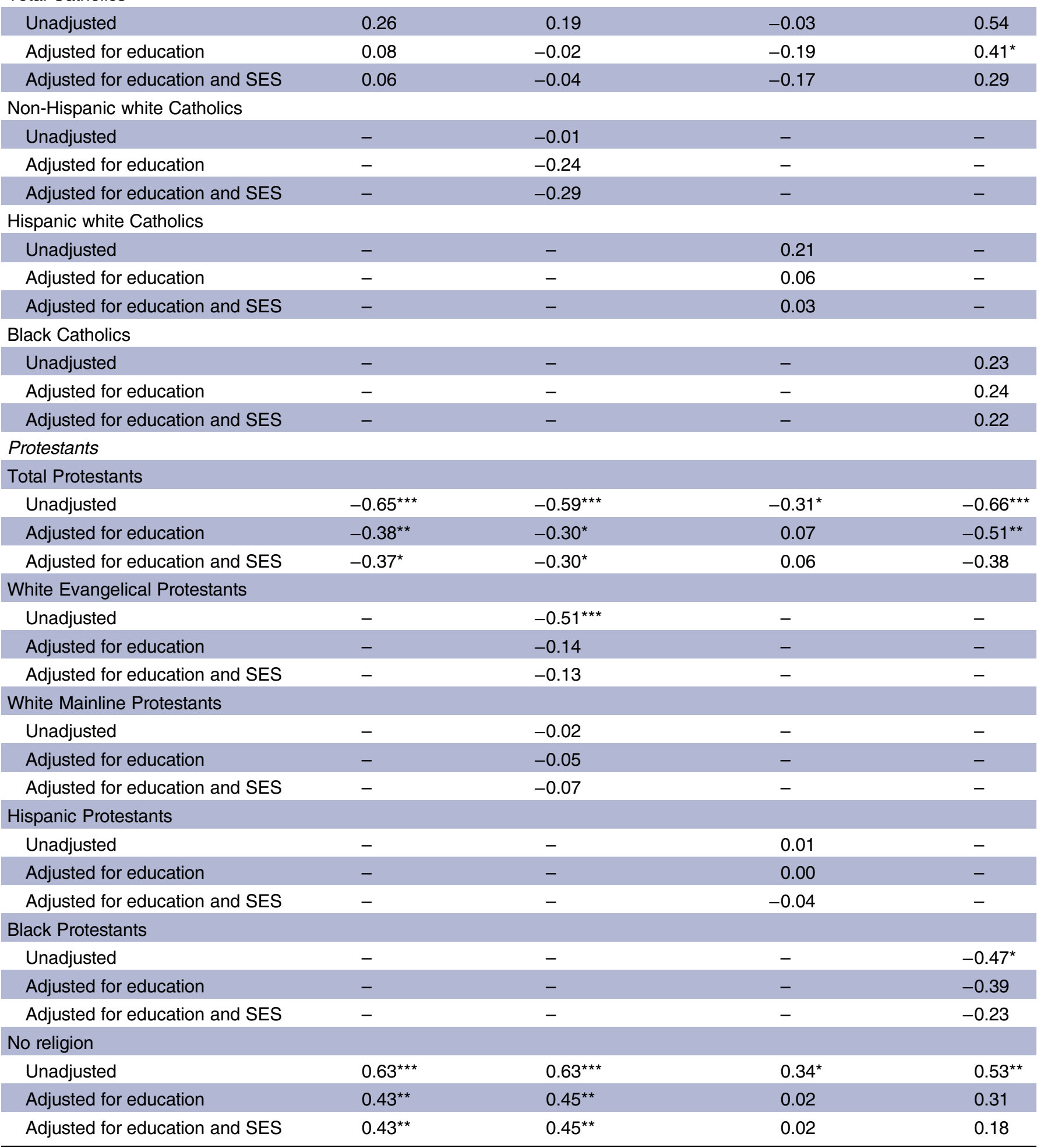

Values are coefficient of Spearman's correlation.

p Values: ${ }^{*}<0.05,{ }^{* *}<0.01,{ }^{\star * *}<0.001$.

SES, socioeconomic status. 
initiation. If confirmed at the individual level, our findings may help improve current breast feeding promotion policies by focusing on the sociocultural expectations, values and support needs concerning infant feeding.

\section{Author affiliations}

${ }^{1}$ Inserm, UMR 1153 Epidemiology and Biostatistics Sorbonne Paris Cité Centre (CRESS), Developmental Origins of Health and Disease (ORCHAD) Team, Villejuif, France

${ }^{2}$ Paris Descartes University, France

${ }^{3}$ Paris-Sud University, Faculty of medicine, Kremlin-Bicêtre, France

${ }^{4}$ CNRS, UMI 3189 Environnement, Santé, Société, Faculté de Médecine Secteur Nord, Marseille, France

${ }^{5}$ CNRS, UMR 7206 Eco-anthropologie et Ethnobiologie, Musée de l'Homme, Muséum National d'Histoire Naturelle, Paris, France

${ }^{6}$ McGill University, Departments of Pediatrics, Montréal, Québec, Canada

${ }^{7}$ McGill University, Departments of Epidemiology, Biostatistics and Occupational Health, Montréal, Québec, Canada

${ }^{8}$ National University of Singapore, Department of Obstetrics and Gynaecology, Yong Loo Lin School of Medicine, Singapore

\section{Handling editor Soumitra Bhuyan}

Acknowledgements The authors thank Jérome Fourquet from the Institut français d'opinion publique for sharing religion data in the French Departments and Professor Catherine Rollet from the Université de Versailles St-Quentin-en-Yvelines for helping us think through our findings and explanations.

Contributors JYB designed the study, collected and analysed the data and wrote a first draft of this manuscript. EC and MSK provided input in study design, data analysis and manuscript writing. All authors interpreted the results, revised the manuscript and approved the final version to be submitted. JYB confirms that he had full access to all the data in the study and had final responsibility for the decision to submit for publication.

Competing interests None declared.

Provenance and peer review Not commissioned; externally peer reviewed.

Data sharing statement The data collected online and used in this manuscript can be shared by the authors on request.

Open Access This is an Open Access article distributed in accordance with the Creative Commons Attribution Non Commercial (CC BY-NC 4.0) license, which permits others to distribute, remix, adapt, build upon this work noncommercially, and license their derivative works on different terms, provided the original work is properly cited and the use is non-commercial. See: http:// creativecommons.org/licenses/by-nc/4.0/

\section{REFERENCES}

1. Hewlett BS, Lamb ME. Hunter-gatherer childhoods: evolutionary, developmental, and cultural perspectives. Transaction Publishers. 2005.

2. Macadam PS, Dettwyler KA. Breastfeeding: biocultural perspectives Transaction Publishers. 1995.

3. Castilho SD, Filho AdAB. The history of infant nutrition. J Pediatr (Rio J) 2010;86:179-88.

4. Victora CG, Bahl R, Barros AJ, et al. Breastfeeding in the 21st century: epidemiology, mechanisms, and lifelong effect. Lancet 2016;387:475-90.

5. Kramer MS. "Breast is best": the evidence. Early Hum Dev 2010;86:729-32.

6. World Health Organization. Global strategy for infant and young child feeding. World Health Organization, 2003.

7. Cattaneo A, Burmaz T, Arendt M, et al. Protection, promotion and support of breast-feeding in Europe: progress from 2002 to 2007. Public Health Nutr 2010;13:751-9.

8. Health Canada. Statistics Canada, Canadian community health survey, 2009-2010. Health Canada, 2012

9. Centers for Disease Control and Prevention. Breastfeeding report card-United States, 2010. 2010. http://www.cdc.gov/breastfeeding/ pdf/breastfeedingreportcard2010.pdf (accessed Mar 2016).
10. Belanoff CM, McManus BM, Carle AC, et al. Racial/ethnic variation in breastfeeding across the US: a multilevel analysis from the National Survey of Children's Health, 2007. Matern Child Health J 2012;16 (Suppl 1):S14-26.

11. Yngve A, Sjostrom M. Breastfeeding determinants and a suggested framework for action in Europe. Public Health Nutr 2001;4:729-39.

12. Tarrant RC, Kearney JM. Breast-feeding practices in Ireland. Proc Nutr Soc 2008;67:371-80.

13. Statistics Canada. Canadian Community Health Survey, 2009-2010. 2012. http://www.hc-sc.gc.ca/fn-an/surveill/nutrition/commun/ prenatal/initiation-eng.php\#a3 (accessed Mar 2016).

14. Schmied V, Barclay L. Connection and pleasure, disruption and distress: women's experience of breastfeeding. J Hum Lact 1999;15:325-34.

15. Hauck YL, Graham-Smith C, Mclnerney J, et al. Western Australian women's perceptions of conflicting advice around breast feeding Midwifery 2011;27:e156-62.

16. Bourdieu P. The logic of practice. Stanford University Press, 1990.

17. Weber M. The protestant ethic and the spirit of capitalism. 1904

18. Durkheim E. Le suicide. Paris: PUF, 1897.

19. Gremillion $\mathrm{H}$. The cultural politics of body size. Annu Rev Anthropol 2005;34:13-32.

20. Ayisi JG, van't Hoog AH, Agaya JA, et al. Care seeking and attitudes towards treatment compliance by newly enrolled tuberculosis patients in the district treatment programme in rural western Kenya: a qualitative study. BMC Public Health 2011; $11: 515$.

21. Dube AR, Stanton CA. The social context of dietary behaviors: the role of social relationships and support on dietary fat and fiber intake. Modern dietary fat intakes in disease promotion. Springer, 2010:31-42.

22. Pew Research Center. Table: Christian Population as Percentages of Total Population by Country. 2011. http://www.pewforum.org/ 2011/12/19/table-christian-population-as-percentages-of-totalpopulation-by-country/ (accessed Mar 2016).

23. Central Intelligence Agency. The World Factbook 2013-2014. Washington DC, 2014.

24. World Health Organization. The WHO Global Data Bank on Infant and Young Child Feeding: infant and young child feeding data by country. 2016. http://www.who.int/nutrition/databases/infantfeeding/ countries/en/ (accessed Mar 2016).

25. Organisation for Economic Co-operation and Development. OECD Family Database: CO1.5 Breastfeeding rates, 2016. 2016. http:// www.oecd.org/els/family/database.htm (accessed Mar 2016).

26. United Nations Development Programme. Human Development Report. 2015.

27. Institut Français d'Opinion Publique. Geographic analysis of the repartition of religions in France [Éléments d'analyse géographique de l'implantation des religions en France]. 2006. http://www.ifop. com/media/poll/religions_geo.pdf (accessed Mar 2016).

28. Direction of Research Studies, Evaluation and Statistics [Direction de la Recherche, des Etudes, de l'Évaluation et des Statistiques, Dress]. Child health certificate on the 8th day [Certificat de Santé de l'enfant au 8e jour, CS8]. Paris, France. 2006-2013. http://www. data.drees.sante.gouv.fr/ (accessed Mar 2016).

29. Central Statistics Office. This is Ireland, Census 2011. Dublin, Ireland, 2012.

30. Healthcare Pricing Office-Health Research and Information Division. Perinatal Statistics Report 2011. Dublin, Ireland 2012:144.

31. General Register Office for Scotland. Census April 2001. 2001. http://www.nrscotland.gov.uk/statistics-and-data/statistics (accessed Mar 2016).

32. Office for National Statistics. Census 2001: General report for England and Wales. 2005.

33. Northern Ireland Statistics \& Research Agency. 2001 Census-Key Statistics. 2001. http://web.ons.gov.uk/ons/datasets-and-tables/ index.html (accessed Mar 2016).

34. United Nations Children's Emergency Fund. UK Breastfeeding Rates. Secondary UK Breastfeeding Rates 2010. http://www.unicef. org.uk/BabyFriendly/About-Baby-Friendly/Breastfeeding-in-the-UK/ UK-Breastfeeding-rates/

35. Statistics Canada. 2011 National Household Survey. 2011. http:// www12.statcan.gc.ca/nhs-enm/2011/dp-pd/dt-td/Rp-eng.cfm? $\mathrm{LANG}=\mathrm{E} \& A P A T H=3 \& D E T A I L=0 \& D I M=0 \& F L=A \& F R E=0 \& G C=0$ \& $\mathrm{GID}=0 \& \mathrm{GK}=0 \& \mathrm{GRP}=0$ \&PID $=105399 \& \mathrm{PRID}=0 \& \mathrm{PTYPE}=105277$ $\& S=0 \&$ SHOWALL $=0 \&$ SUB $=0 \&$ Temporal $=2013 \&$ THEME $=95 \&$ $\mathrm{VID}=0 \&$ VNAMEE $=\&$ VNAMEF $=($ accessed Mar 2016)

36. Public Religion Research Institute. American Value Atlas project 2014. http://ava.publicreligion.org/home (accessed Mar 2016). 
37. Burdette AM, Pilkauskas NV. Maternal religious involvement and breastfeeding initiation and duration. Am J Public Health 2012;102:1865-8.

38. Weber M. Economy and society: an outline of interpretive sociology. Univ of California Press, 1978

39. Schuman AJ. A concise history of infant formula (twists and turns included). Contemp Pediatr 2003:20:91-8.

40. De Garine I, Pollock NJ. Social aspects of obesity. Routledge, 1995.

41. Badinter E. L'Amour en plus. Flammarion, 1980.

42. Fildes V. Breasts, bottles and babies-a history of infant feeding. Edinburgh University Press, 1986.

43. Hoefer C, Hardy MC. Later development of breastfed and artifically fed infants: comparison of physical and mental growth. J Am Med Assoc 1929;92:615-20.
44. Rumeau-Rouquette $\mathrm{C}$, Crost M, Bréart G, et al. Evolution de l'allaitement maternel en France entre 1972 et 1976. Arch Fr Pediatr 1980;37:331-5.

45. Nathoo T, Ostry A. The one best way?: breastfeeding history, politics, and policy in Canada. Wilfrid Laurier University Press, 2011.

46. Wolf $\mathrm{JH}$. Low breastfeeding rates and public health in the United States. Am J Public Health 2003;93:2000-10.

47. Hofvander Y, Sjölin S. Breast feeding trends and recent information activities in Sweden. Acta Paediatrica 1979;68:122-5.

48. Weber M. The sociology of religion. Beacon Press, 1993.

49. Scott JA, Kwok YY, Synnott K, et al. A comparison of maternal attitudes to breastfeeding in public and the association with breastfeeding duration in four European countries: results of a cohort study. Birth 2015;42:78-85. 